Article

\title{
The Cape Wetland Restionaceae of New Years Peak under a Changing Climate
}

\author{
James A. Ayuk ${ }^{1,2, *}$, Lincoln M. Raitt ${ }^{2}$, Guy Midgley ${ }^{3}$, Martin Chari ${ }^{1}$ and Ahmed M Kalumba ${ }^{1}$ \\ 1 Risk and Vulnerability Science Centre, University of Fort Hare, Private Bag X1314, Alice 5700, South Africa \\ 2 Department of Biodiversity and Conservation Biology, University of the Western Cape, Private Bag X17, \\ Bellville 7535, South Africa \\ 3 Department of Botany and Zoology, Stellenbosch University, Private Bag X1, Matieland 7602, South Africa \\ * Correspondence: jaayuk@gmail.com, jayuk@ufh.ac.za
}

\begin{abstract}
The Cape Restionaceae species, an endemic of the Fynbos Biome, is threatened by urbanization, alien plant invasion, agricultural expansion, and groundwater extraction. This is further worsened by the semi-arid conditions and hydrological variability factors, which influences species niche dynamics. Therefore, it is important to assess and monitor the Restionaceae species for preservation of their endemism and richness. This study models the hydrological niche and distribution changes of Restionaceae species at the New Years Peak (NYP) at microclimate level for biodiversity conservation. MaxEnt modelling and GIS analytical approaches were applied at various stages in niche modelling process as follows: (i) microclimatic input raster layers' generation, (ii) ecological modelling and hydrological niche manipulation, and (iii) spatial distributional change mapping. The hydrological niches of the Restionaceae were effectively examined under the recent climate and compared with RCP2.6 and RCP8.5 future climate scenarios as the microscale environmental inputs. The results showed that most of the studied Restionaceae species positioned themselves along a hydrological gradient. Each species tolerated a range of hydrological conditions, which formed their hydrological niche. Changing climate would cause both positive and negative species range shifts. The study assists in plant species conservation and future climate change impact analysis on endangered plant species.
\end{abstract}

Keywords: Microclimate; Water table depth; Climate change impacts; Cape Restionaceae; Species Distribution Modelling; MaxEnt

\section{Introduction}

The loss of biodiversity continues to be a challenge owing mainly to the negative impacts of climate change and anthropogenic actions on species and ecosystems [1]. Globally, the predicted ultimate percentage loss of plant species due to climate change has varied between studies $[2,3]$ with the most impacted plant species being those in the Mediterranean climate regions [4]. Africa is experiencing a decline in diversity within species, between species and of ecosystems [5]. Also, studies have revealed the potential impact of climate change and land transformation on plant diversity in the Cape Floristic Region (CFR) [6]. Indeed, research has shown that, climate change effects have affected biodiversity through range shifts and alteration of phenology [7, 8]. In addition, plant species such as the Cape Restionaceae along with other plants in the Fynbos Biome are threatened by urbanization, agricultural expansion, alien plant invasion and groundwater abstraction from sandstone aquifers which underlie the fynbos communities [9]. This is very dynamic and complex in a semi-arid environment. Furthermore, current trends in the seasonal distribution of available moisture in the southern African region indicate that the area is highly vulnerable to climate change [10] which poses a threat to the hydrologic resources. Indeed, global climate change models predict drastic drifts in climatic trends by the year 2100 [11]. This, in turn, will affect precipitation in the CFR and, as a consequence, plant available moisture may become much more seasonal in the 
southern African region resulting in likely shifts in plant community distribution and composition [12].

Most studies of the potential impacts of climate change on species niches have been at global to regional scales using bioclimatic variables as opposed to being at microscale and using localised variables like hydrological variables. A niche is how a species fits into an ecological community or ecosystem, and is modelled through the environmental variables [13]. The Restionaceae tolerate a wide range of water regimes along the hydrological gradient which allows them to successfully cohabit within mixed plant communities [14,15] making them a suitable candidate for hydrological change impact analysis. For instance, Restionaceae species in seasonally saturated habitats have been observed to effectively segregate along hydrological gradients [16]. This is attributed to their differential tolerance of excess soil wetness or dryness [17]. Since South Africa is a semi-arid environment, hydrological factors are considered a major environmental influence in structuring plant species niches [18].

An understanding of how the spatial distribution of Restionaceae species at a local scale is related to soil hydrology and knowledge of the impacts of anthropogenically induced hydrological changes should inform effective management and planning strategies for monitoring the species natural abundance trends in the future $[19,20]$. With such knowledge, any possible devastation could be assessed and potentially be controlled through adequate monitoring and interventions [21]. Ecological (species) niche models can be used to quantify the impact of climatic changes subsequent to an understanding of water regime requirements in Restionaceae communities. This is crucial for the Cape Floristic Region (CFR) an internationally recognised biodiversity hotspot [22], centre of endemism [23,24], with a highly heterogeneous relief, very diverse soil types and widely varied local climate [23]. Essentially, this could save about 480 species globally with 330 species occurring in Africa, 150 species in Australia, four species in New Zealand, one species found in South East Asia and one in South America [25], which have survived more than 65 million years [26]. To this end, robust analysis and modelling is needed to provide valid information for proper conservation and management.

Advancements in GIS have revolutionised species predictive modelling by significantly improving the abilities to capture, manage, analyse and visualise now increasingly digitally-captured biodiversity resource data [27]. GIS has offered natural resource managers and biological conservationists with improved techniques to analyse data of different origins and to generate increasingly required spatial continuous data of environmental variables [28]. New techniques with improved data analytical capabilities have afforded researchers the opportunity to quantitatively map and test species distributions based on their association with the environment [29]. Species models based upon the association between species and their environment, have become reliable tools for conservation and management [30]. Furthermore, by integrating statistical algorithms and spatial analysis, GIS provide the means to rapidly analyse the distribution status of a species even from limited field data [31]. In general, GIS tools have been used extensively for preparing the inputs and in processing of modelled outputs of ecological data. The procedures for implementing kriging, for instance, do incorporate semivariogram or covariance models, measures of error and uncertainty when estimating spatial relationships [32-34]. Therefore, these approaches have been fundamental in providing much needed information about the species dynamics. In this study, we model the species niche through hydrological variables using mixed methods with an overall reliance on GIS for data manipulation, analysis and output generation. To explore the idea of the hydrological niche of plant species, the hydrological variables used are (i) water table depth, and (ii) the relative elevation is also used as an additional variable. This study generates its own microclimate hydrological data sets for modelling species niche, based on the above variables.

\section{Study area}

The study area is a New Year Peak (NYP) wetland community in the southwest Fynbos Bioregion near the city of Cape Town in the Western Cape Province of South Africa (Figure 1). It is located at $-33^{\circ} 41^{\prime} 20^{\prime \prime}$ S, 1906 $03^{\prime \prime}$ E coordinates and at elevation 1080 metres above sea level. The 
climate is Mediterranean, which is characterised by rainfall seasonality with cold, wet winters and dry warm summer month on each half of the year [35]. Geologically defined by Hawequas sandstone units with acidic lithosol soils derived from Ordovician sandstones of the Cape Supergroup. The study sample site comprised of 233 equally-spaced 1-square-metre quadrats (sample points) placed 1 metre from each other. These quadrat sites offered measurements of elevation and water table depth along with locational data of the presence or absence of Restionaceae species were collected from each quadrat as described by [16].

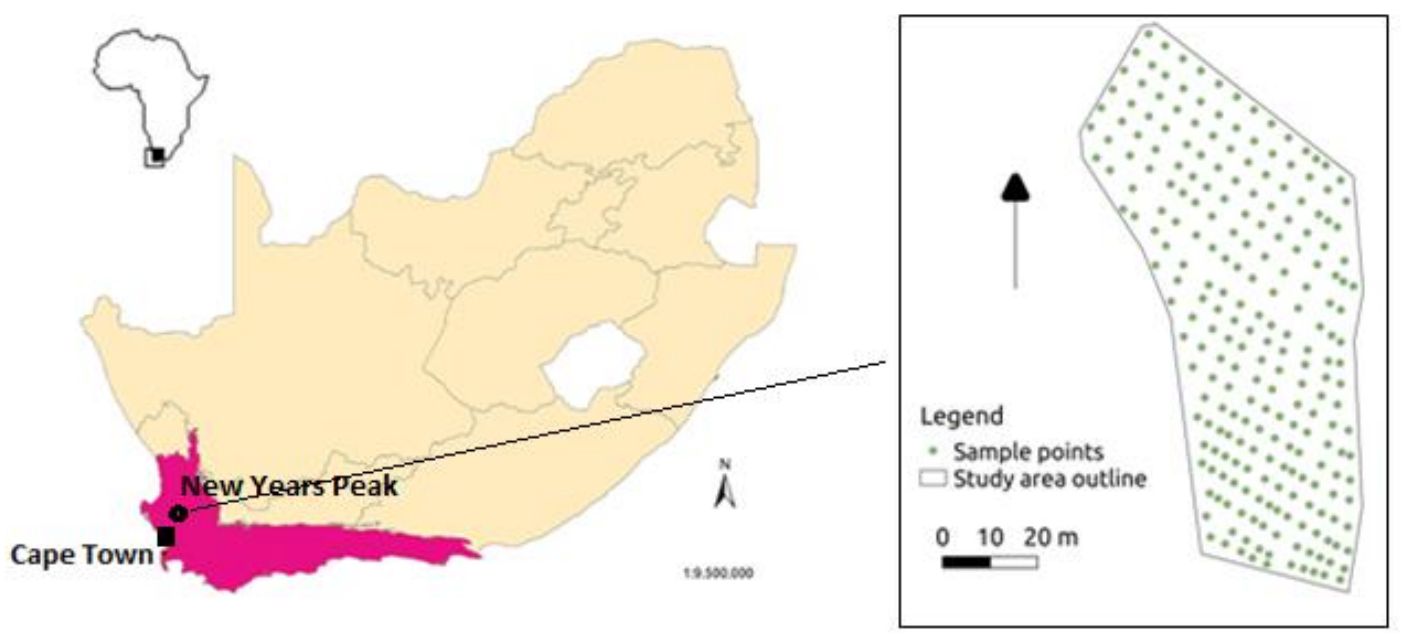

Figure 1. Study location the CFR in South Africa and distribution of sample points in the study area.

\section{Materials and Methods}

\subsection{Biological data}

The vegetation data included the presence or absence from the 223 sample sites. Twelve Restionaceae species were recorded. These included Anthochortus crinalis (Mast.) H.P. Linder, Askidiosperma nitidum (Mast.) Linder, Elegia coleura (Nees) ex Mast., Elegia filacea Mast., Elegia neesii Mast., Hypodiscus aristatus (Thunb.) C. Krauss, Restio bolusii Pillans, Restio curviramis Kunth, Restio miser Kunth, Restio obscurus Pillans, Restio pedicellatus Mast. and Staberoha cernua (L.f.) T. Durand \& Schinz.

\subsection{Environmental variables}

The mean depth to the water level in the soil measured from a network of dip wells within the site reflected the recent hydrological regime of the soil from 2007 to 2011. To project the future, statistically downscaled time series Raw GCM CMIP5 daily point data for 2020 - 2100 from Planck Institute for Meteorology (MPI-ESM) model provided by the CGIAR Research Program on Climate Change Agriculture and Food Security (CCAFS) was used. The MPI-ESM model consists of three climatic variables, namely, precipitation $(\mathrm{mm})$, temperature $\left({ }^{\circ} \mathrm{C}\right)$ and solar radiation $\left(\mathrm{W} / \mathrm{m}^{2}\right)$, and is well suited for Southern Africa climate predictions [36]. For comparative view of different future scenarios, projected simulations forced with two representative pathways (i.e. RCP2.6 and RCP8.5) were used to simulate a possible range of radiative forcing values of $+2.6 \mathrm{~W} / \mathrm{m}^{2}$ and $+8.5 \mathrm{~W} / \mathrm{m}^{2}$, respectively, in the future relative to pre-industrial values. $\mathrm{RCP} 2.6$ assumes that global annual emissions measured in $\mathrm{CO}_{2}-$ equivalents peak by 2020 and then decline thereafter, and RCP 8.5 assumes emissions continue to rise throughout the 21st century [37]. The RCP2.6 scenarios was good but an unlikely future scenario, while the RCP8.5 was a more realistic future scenario based on the present human activity. Precipitation (P) is the primary source of the soil moisture. As such a future climate signal was mathematically calculated from the current and future $P$ following [38]. This procedure obtained the ratio between the current and future annual average $P$ and multiplying it by the observed mean water table depth (MWTD) to obtain 
an estimate of the future climate signal (i.e. future WTD) for each quadrat. All daily these records were aggregated into annual averages to render the MWTD.

Elevation has a direct influence on the moisture hydraulics in the soil by providing the down slope gradient that moisture pursues [39]. On site topographical elevation (in metres) were read from the centre of each quadrat by means of survey equipment [16] and used to verify the presence of a topographical gradient.

\subsection{Preparation of microclimatic layers}

Due to the non-applicability of Worldclim (large grid) bioclimatic data for modelling species niches at the local level or plot scale, unique microclimate hydrological data layers needed to be generated. Accessory software tools like Microsoft Excel ${ }^{\odot}$, ESRI ArcGIS ${ }^{\odot}$ and Notepad ${ }^{\odot}$ were used to prepare the environmental layers needed to model the relationships between species and the measured environmental variables. Maximum Entropy algorithms of MaxEnt software version 3.3.3K were used for species modelling [31, 40]. MaxEnt requires that all spatial inputs are in ASCII raster grid format, of the same cell size, extent and coordinate system (geographic or UTM) and a background layer. The $x-y$ coordinates, observed current MWTD and the estimated future MWTD for each quadrat respectively populated separate columns in an Excel spreadsheet that was later saved as comma separated values $\left({ }^{*}\right.$. csv ) files. ArcGIS 10.3 geostatistical analysis tools used ordinary kriging interpolation to convert points into continuous surfaces as well as to modify the kriged layers to the same geographic coordinate system, extent and cell size [41]. The latter is a strict requirement for the MaxEnt processes. The following steps were involved during the conversion into continuous surfaces: (i). the Add X-Y Data tool was used to add environmental data (MWTD and elevation) in *.csv format as spatial $\mathrm{x}-\mathrm{y}$ coordinate Event points and then saved as ESRI Shapefiles. (ii) Spatial Analyst Tools used ordinary kriging techniques and calculated very high resolution continuous grid surfaces of identical scale unit from the point layers. Note that these kriged surfaces possessed very minute (well below $1 \mathrm{~m}$ ) grid sizes, which made them unique and different from frequently utilised mainly regional or global (very large) scale bioclimatic surfaces for species habitat modelling (e.g. [42]. (iii) The resultant continuous raster surfaces were masked to the site boundary outline using extraction tools. (iv) Layers were projected to the WGS84 datum and the Universal Transverse Mercator (UTM) projection (zone 34S) systems. (v) ‘ Raster to ASCII' conversion tools were used to convert environmental layers into ASCII format ( ${ }^{*}$.asc). ASCII grid layers were saved in a 'ASCII_Environmental_layers' folder in readiness for the MaxEnt run.

\subsection{Defining MaxEnt Background Selection}

Species niche modelling generally relies on background data or pseudo absences or bias samples when developing a distribution model [43]. The background is literally the total extent of the sampled area covering both where species were spotted and where they were not counted. A minimum convex (hull) boundary (MCB) defined an outline polygon feature for each species then converted into raster layers using 'Polygon to Raster' conversion tools in a GIS. Using Spatial Analyst Tools and Map Algebra, the background layers were reclassified into new binary layers wherein species MCBs were assigned a value of 1 and a value of "NoData" elsewhere within the plot outline boundary polygons. This provided MaxEnt with a background file with the same bias as the presence locations. The following conditional (Con) statement was entered into the Raster calculator window for this purpose:

Con ("bias_file" $>=0,1$, , bias_file")

The con statement instructs to: "Convert all pixels with values 0 to values 1 and pixels with other values (mostly the no data cells) should remain as they are".

Thereafter, the resulting polygon was converted into ASCII grid files with the same extent, cell size, snap raster and mask dimensions similar to the other ASCII files for entry into MaxEnt.

\subsection{Hydrological niche modelling using MaxEnt}

A hydrological niche model represents the relationship between species and the local hydrological (environmental) conditions at occurrence points. The MaxEnt (Maximum Entropy) software version 
3.3.3K [44, 45] freely sourced from http://biodiversityinformatics.amnh.org/open_source/maxent/ was used to create hydrological niche models for Restionaceae species. This algorithm estimates the maximum entropy probability distribution function that is used to predict the probability of species occurrences based on environmental constraints at species (presence) locations [46]. Literally, MaxEnt figures out the relationship between an organism and the environment in which it is known to occur, and uses this relationship to predict other times or places which may be suitable for the organism. The software is designed to suit any sample size and spatial scale. $75 \%$ of the species occurrences were used for model training while $25 \%$ was used for testing the model performance. Four replicate model runs were executed for each species model using a threshold rule of 10 percentile training presence [47]. During each replicate run, subsamples with samples that showed sample bias were removed from the process $[48,49]$. The validation of resultant species models was explained their Area Under the Receiver Operating Characteristic (ROC) Curve (AUC) that ranges from 0 to 1. Models with AUC of 0.6 and above were considered useful model [50].

\subsection{Post-modelling analyses}

Post-analytical procedures included (i) using a logistic threshold probability of occurrence to discriminate species likely presence from absence pixels, and (ii) defining species distributional change maps between the current and future climatic scenarios.

\subsubsection{Defining suitable and non-suitable hydrological niches using GIS}

The MaxEnt modelling processes produced a variety of result outputs among which were continuous raster layers with pixel values ranging from 0 (lowest probability of occurrence) to 1 (highest probability of occurrence). Based on a '10 percentile training presence' probability threshold these pixelled layers were reclassified into binary layers that distinguished pixels of probable species presence (niche suitability) from those of probable absence (non-suitability) [51]. ASCII to Raster tools were used to convert the resulting binary outputs from *.asc into *.tiff format. Finally, map tools were employed to edit and display comparable suitable and unsuitable hydrological niche maps.

\subsubsection{The distributional change maps}

The change between the current and the future species models for each species was computed by subtracting the current potential (binary) distribution from the future RCP scenario projections using the Map Algebra tool suite. (E.g. the following expression in the Map Algebra calculation window ["species1_rcp85.tif" - "species1_cur.tif"] calls for a new change raster map where, species1_rcp85 is the future potential distribution and species1_cur is the current potential distribution of a species). The result was a change map, which contained pixels that extended beyond the current range and vice versa. The resulting raster maps depict predicted expansion (gain in species occurrences as ' +1 '), contraction (loss of habitat as ' -1 '), and areas of stability which showed no change in the species distribution as ' 0 '. Overlaying the change maps on the current species distribution layer gave a spatial impression of these changes in the map window. These change maps illustrated the anticipated changes in each species' distribution range from the potential current distribution to the projected distribution by the end of the century (2100).

\section{Results and Discussions}

\subsection{Environmental surfaces}

The map processing tools of ArcGIS ${ }^{\circledR}$ software successfully generated microclimatic surfaces for all environmental variables. Figure 2(a) indicates the presence of an elevation gradient which is sloping south-eastwards of the site. Relative elevation was derived from a reference point located within the study site. Figure 2(b) shows an uneven distribution moisture pattern and reflects a soil moisture gradient of water table depth ranging between 0.1 and $0.7 \mathrm{~m}$. The darkest colour shades indicate the highest values and lighter colour shades represented the low values for both elevation and MWTD. 
High MWTD values correspond with elevated parts of the plot and indicate low water table levels which signify dry conditions and vice versa. This is a direct function of gravity whereby moisture flows and accumulates down the slope gradient [39]. Moisture pattern tends to show a hydrological gradient $[16,17]$ which in turn explains the species current distribution patterns [52-54].

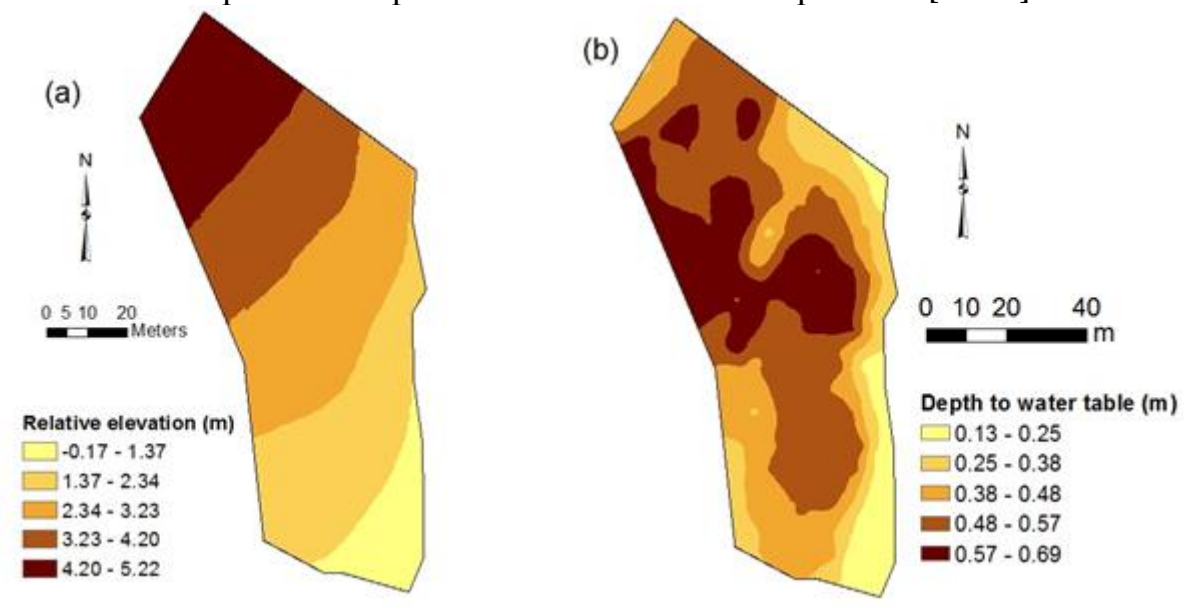

Figure 2. Continuous surfaces of (a) relative elevation, and (b) mean water table depth (MWTD) measured at New Year's Peak.

\subsection{Species distributional change maps}

As expected, the species which were identified in this study have different hydrological preferences with a range of wet and dry conditions [55]. Species niche models show that most species exhibited unique responses in relation to water level variability. In general, there are marked contrasts between the ranges of fundamental and realised niches of individual species as shown in first panel (i.e.1(a) - 10(a)) of Figure 3. The realized niches of species were more restricted and confined to narrower ranges of water depth and variability. The fundamental niches which are the potential distribution are mostly larger in extent and occupy space beyond the observed (realised) species niches. There are extensive overlaps between the predicted fundamental niches of most species which indicate the likelihood of competition for space. Current distributions of species suggest segregation occurred probably as a consequence of competition or adaptation. The panel diagram shows differences in species distribution between the present and two future climate scenarios. Generally, most species show distributional change going into the future. Two species, i.e. Hypodiscus aristatus and Staberoha cernua, remained unchanged or relatively unchanged. This might indicate resilience as these may persist amidst adverse climate conditions in the future. Species that might possibly experience shifts included Anthochortus crinalis, Elegia coleura, Elegia neesii, Restio curviramis and Restio obscurus. Shifting species are migrating species, which show a potential to disappear where conditions become unsuitable but recolonize areas where conditions seem favourable. Future climate changes might favour R. obscurus, $R$. bolusii and $R$. miser. These three species might expand their ranges in the future while maintaining their current ranges. All forms of change will be more severe under the RCP8.5 scenario conditions. The most significant loses would be experienced by E. coleura with up to $24 \%$ loss of habitat. The rest of the species models exhibit relatively minute change compared with their current ranges. 

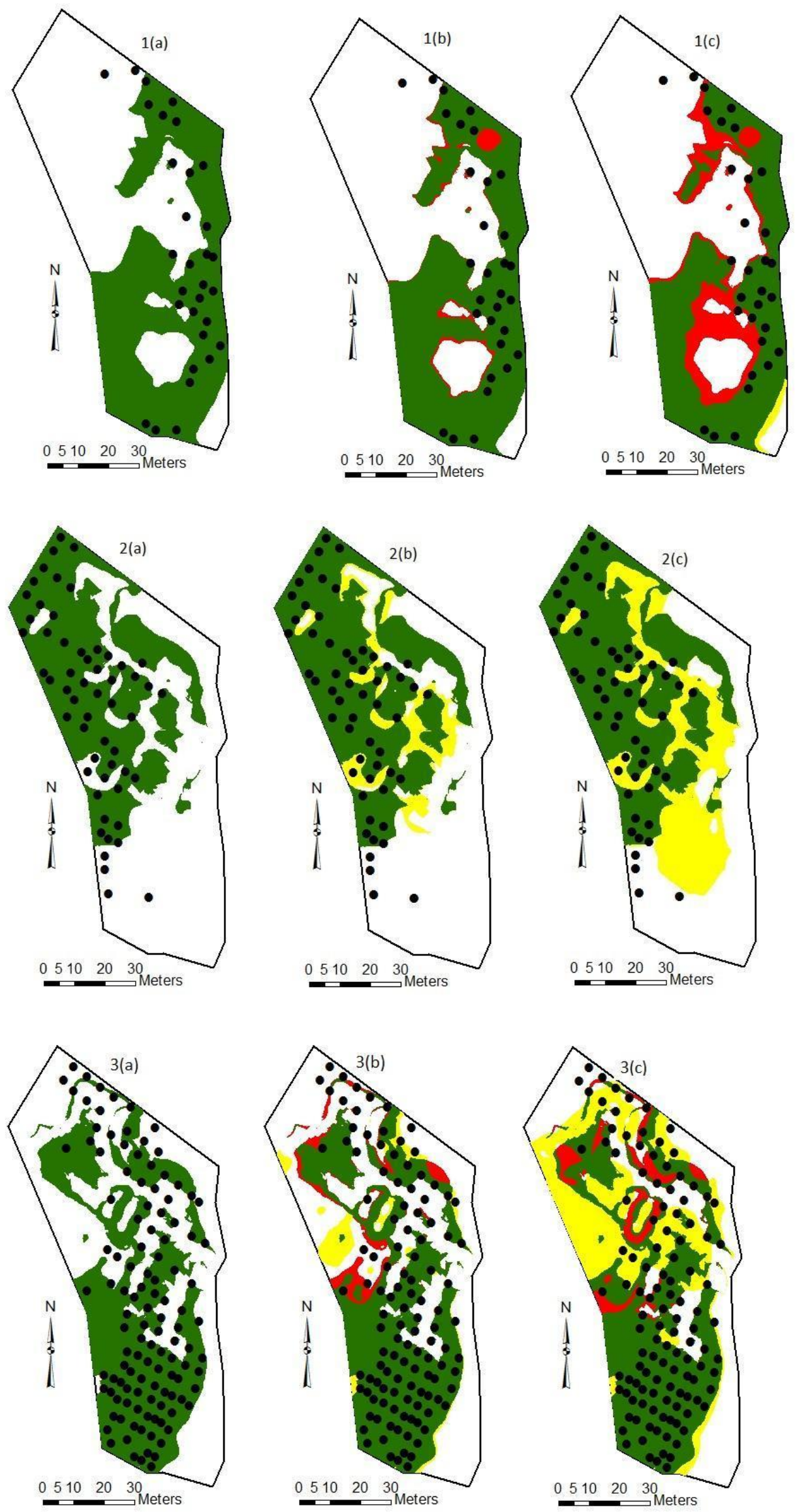

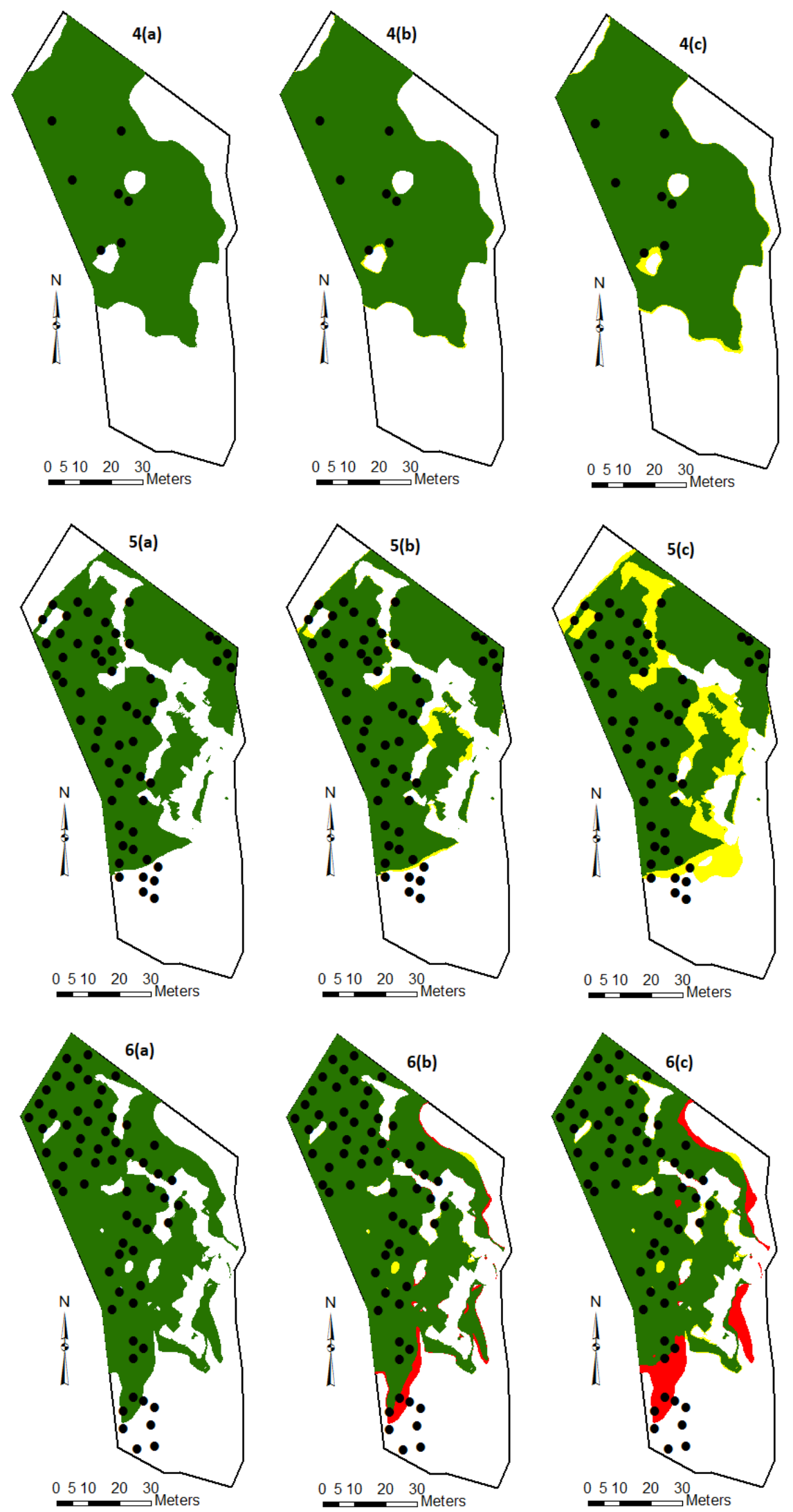

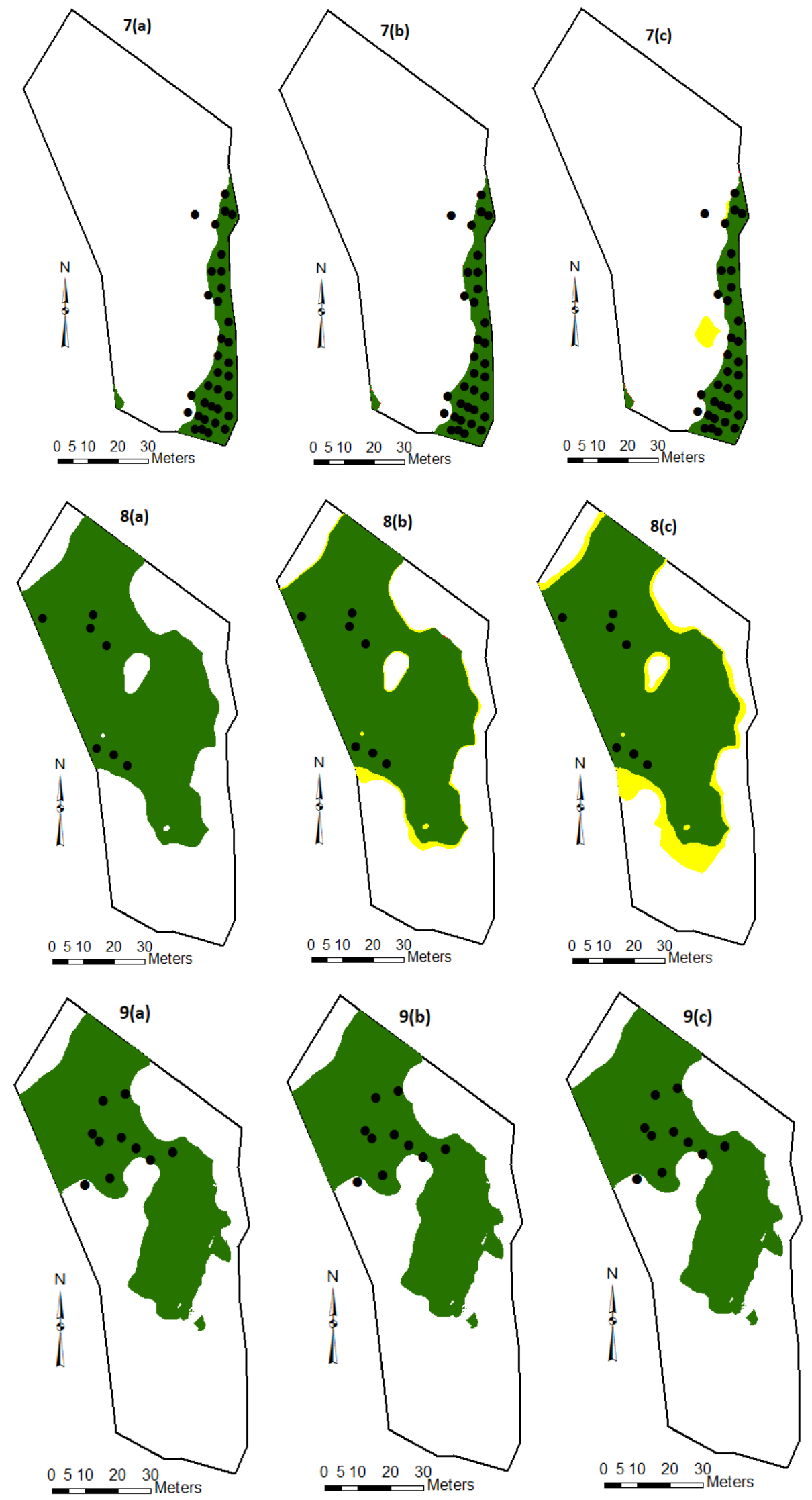

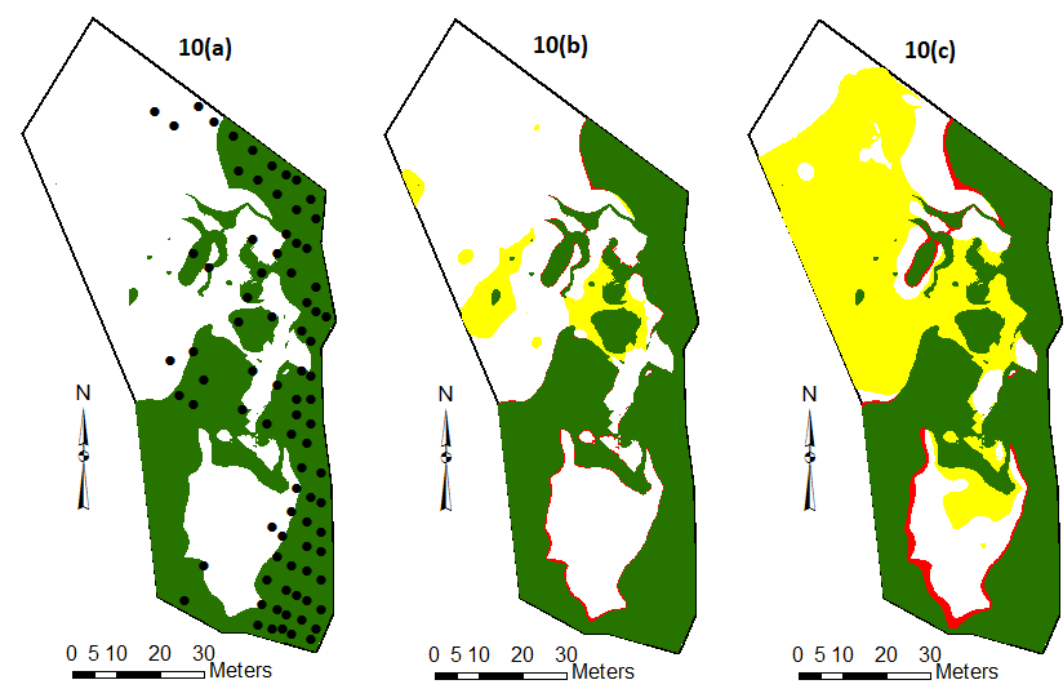

Figure 3. Possible distributional change in hydrological niche of Restionaceae species. $1=$ Elegia coleura; $2=$ E. filacea; $3=$ E. neesii; $4=$ Hypodiscus aristatus; $5=$ Restio boluscii; $6=R$. curviramus; $7=R$. miser $; 8=R$. obscurus; $9=$ Staberoha cernua $; 10=$ Anthochortus crinalis. a, b, c respectively represents the current two future climate conditions. Green, red and yellow surfaces respectively represent the stable, lost and gained distributions.

\section{Conclusions}

GIS tools are efficient in preparing and processing of ecological data that is used during species modelling. These were used to generate hydrological niches of African Restionaceae species. For instance, the future RCP 2.6 and 8.5 climate scenario-values differed significantly in the study area. Both RCPs in turn caused significant changes in the hydrological niches of most sites by 2100. In comparison, RCP 8.5 scenarios result in more severe changes than RCP 2.6. Most species have been shown to have their own hydrological niches, which indicates that they each have individual hydrological requirements although they all coexist in their habitats. The impact of climate change on species varied for individual species. Species showed the full range of possible changes that might occur as responses to climate change including gains, losses, shifts and stability in the projected ranges. In general, the changes appear not to result in the loss of species but rather in range shifts. Care is, however, taken when making general inferences based on the perceived species responses from modelling because these models were created from trained conditions. In most sites the change in climate is expected to introduce novel conditions which are totally outside of the hydrological ranges known today.

In general, in this study, a number of GIS techniques were employed in ecological analysis to generate hydrological niches of African Restionaceae species in micro scale. Most species share the same hydrological niches and may behave differently with respect to each other as environmental conditions change. In addition, the study shows that hydrological variability could actually cause some differences in the future distribution of most species while some resilient ones would maintain their current location or expand into new areas. However, hydrological variables are not the only ones to influence on species distributional behaviour, and therefore, future studies should expand on the set of potentially important variables like aspect and soil properties. These, therefore, do not in any way represent the impact of changes in the hydrological gradient on all species of Fynbos in the CFR. It is possible that the same analytical procedures performed on an expanded set of ecosystems would reveal similar results. This would necessitate additional monitoring over a long period of time to provide more reliable data from further sampling.

Author Contributions: Conceptualization, James Ayuk, Lincoln Raitt and Guy Midgley; Data curation, James Ayuk; Formal analysis, James Ayuk; Funding acquisition, Guy Midgley; Methodology, James Ayuk and Martin Chari; Software, Martin Chari; Supervision, Lincoln Raitt and Guy Midgley; Validation, Lincoln Raitt and 
Ahmed Mukalazi Kalumba; Visualization, Guy Midgley; Writing - original draft, James Ayuk; Writing - review \& editing, Lincoln Raitt, Guy Midgley, Martin Chari and Ahmed Mukalazi Kalumba.

Acknowledgements: The authors thank Yoseph N. Araya and Jonathan Silvertown of the Open University United Kingdom for their pioneering work of hydrological niche in plant communities in the Fynbos biome. The authors acknowledge funding from the Leverhulme Trust and the Darwin Initiative (Defra) for collecting species and hydrological data, and the South African National Biodiversity Institute (SANBI) for resources.

\section{References}

1. UNEP-WCMC, The State of Biodiversity in Africa: A mid-term review of progress towards the Aichi Biodiversity Targets, in UNEP-WCMC (United Nations Environmental Programme - World Conservation Monitoring Centre). . 2016: Cambridge, UK.

2. Thomas, C.D., et al., Extinction risk from climate change. Nature, 2004. 427(6970): p. 145-148.

3. Chen, I.-C., et al., Rapid range shifts of species associated with high levels of climate warming. Science, 2011. 333(6045): p. 1024-1026.

4. Thuiller, W., et al., Climate change threats to plant diversity in Europe. Proceedings of the National Academy of Sciences of the United States of America, 2005. 102(23): p. 8245-8250.

5. Intergovernmental Science-Policy Platform on Biodiversity and Ecosystem Services, I., The IPBES regional assessment report on biodiversity and ecosystem services for Africa. 2018.

6. Midgley, G.F., et al., Developing regional and species-level assessments of climate change impacts on biodiversity in the Cape Floristic Region. Biological Conservation, 2003. 112(1-2): p. 87-97.

7. Fahrig, L., EFFECTS OF HABITAT FRAGMENTATION ON BIODIVERSITY. Annual Review of Ecology, Evolution, and Systematics, 2003. 34(1): p. 487-515.

8. de Chazal, J. and M.D.A. Rounsevell, Land-use and climate change within assessments of biodiversity change: A review. Global Environmental Change, 2009. 19(2): p. 306-315.

9. Rouget, M., et al., Current patterns of habitat transformation and future threats to biodiversity in terrestrial ecosystems of the Cape Floristic Region, South Africa. Biological Conservation, 2003. 112(1-2): p. 63-85.

10. Williams, C.J., D.R. Kniveton, and R. Layberry, Assessment of a climate model to reproduce rainfall variability and extremes over Southern Africa. Theoretical and Applied Climatology, 2010. 99(1-2): p. 9-27.

11. IPCC, Summary for Policymakers, in Climate Change 2007: The Physical Science Basis. Contribution of Working Group I to the Fourth Assessment Report of the Intergovernmental Panel on Climate Change, S. Solomon, D. Qin, M. Manning, Z. Chen, M. Marquis, K.B. Averyt, M.Tignor and H.L. Miller, Editor. 2007, Cambridge University Press: Cambridge, United Kingdom and New York, NY, USA.

12. Zedler, J.B., How frequent storms affect wetland vegetation: a preview of climate-change impacts. Frontiers in Ecology and the Environment, 2010. 8(10): p. 540-547.

13. Polechová, J. and D. Storch, Ecological Niche, in Encyclopedia of Ecology, S.E. Jørgensen and B.D. Fath, Editors. 2008, Academic Press: Oxford. p. 1088-1097.

14. Linder, H.P., B.G. Briggs, and L.A.S. Johnson, Restionaceae, in The Families and Genera of Vascular Plants IV. Flowering Plants: Monocotyledons, K. Kubitzki, Editor. 1998, Springer: Berlin. p. 425-445.

15. Hardy, C.R., P. Moline, and H.P. Linder, A phylogeny for the African restionaceae, and new perspectives on morphology's role in generating complete species phylogenies for large clades. Int. J. Plant Sci, 2008. 169: p. 377-90.

16. Araya, Y.N., et al., A fundamental, eco-hydrological basis for niche segregation in plant communities. New Phytologist, 2011. 189(1): p. 253-258.

17. Silvertown, J., et al., Hydrologically defined niches reveal a basis for species richness in plant communities. Nature, 1999. 400(6739): p. 61-63.

18. Guo, D., et al., Hydrological Niche of Restionaceae Species in Silvermine South Africa. JWRHE Journal of Water Resource and Hydraulic Engineering, 2015. 4(3): p. 286-292.

19. Ferreira, S., et al., From numbers to ecosystems and biodiversity: A mechanistic approach to monitoring. Koedoe, 2011. 53: p. 187-198.

20. Ehrlén, J. and W.F. Morris, Predicting changes in the distribution and abundance of species under environmental change. Ecology Letters, 2015. 18(3): p. 303-314.

21. Huntley, B., et al., Potential impacts of climatic change upon geographical distributions of birds. Ibis, 2006. 148: p. 8-28. 
22. Myers, N., et al., Biodiversity hotspots for conservation priorities. Nature, 2000. 403(6772): p. 853-858.

23. Goldblatt, P. and J.C. Manning, Plant diversity of the Cape region of southern Africa. Annals of the Missouri Botanical Garden, 2002: p. 281-302.

24. Rebelo, A.G., et al., Fynbos biome, in The Vegetation of South Africa, Lesotho and Swaziland, L. Mucina and M.C. Rutherford, Editors. 2006, South African National Biodiversity Institute Pretoria. p. 53-219.

25. Cowling, R.M., et al., Plant diversity in mediterranean-climate regions. Trends in Ecology \& Evolution, 1996. 11(9): p. 362-366.

26. Bremer, K., Gondwanan evolution of the grass alliance of families (Poales). Evolution, 2002. 56(7): p. 13741387.

27. Vogiatzakis, I.N., GIS-based modelling and ecology: a review of tools and methods. 2003: Citeseer.

28. Li, J. and A.D. Heap, Spatial interpolation methods applied in the environmental sciences: A review. Environmental Modelling \& Software, 2014. 53: p. 173-189.

29. Brotons, L., et al., Presence-absence versus presence-only modelling methods for predicting bird habitat suitability. Ecography, 2004. 27(4): p. 437-448.

30. Austin, M., Species distribution models and ecological theory: A critical assessment and some possible new approaches. Ecological Modelling, 2007. 200(1-2): p. 1-19.

31. Phillips, S.J., R.P. Anderson, and R.E. Schapire, Maximum entropy modeling of species geographic distributions. Ecological Modelling, 2006. 190(3): p. 231-259.

32. Goovaerts, P., Geostatistical tools for characterizing the spatial variability of microbiological and physicochemical soil properties. Biology and Fertility of soils, 1998. 27(4): p. 315-334.

33. Isaaks, E. and R.M. Srivastava, Applied Geostatisties. 1989, Oxford Univ. Press. New York, USA.

34. Ahmadi, S.H. and A. Sedghamiz, Application and evaluation of kriging and cokriging methods on groundwater depth mapping. Environ Monit Assess Environmental Monitoring and Assessment: An International Journal Devoted to Progress in the Use of Monitoring Data in Assessing Environmental Risks to Man and the Environment, 2008. 138(1-3): p. 357-368.

35. Mucina, L. and M.C. Rutherford, The vegetation of South Africa, Lesotho and Swaziland. 2006: South African National Biodiversity Institute.

36. Connolley, W.M. and T.J. Bracegirdle, An Antarctic assessment of IPCC AR4 coupled models. Geophysical Research Letters, 2007. 34(22).

37. Van Vuuren, D.P., et al., The representative concentration pathways: an overview. Climatic change, 2011. 109(12): p. 5 .

38. Guo, D., et al., Climate change impacts on hydrological niches of Restionaceae species in Jonkershoek, South Africa. Journal of Water Resource \& Hydraulic Engineering, 2016. 5(1): p. 20-28.

39. Dingman, S.L., Physical hydrology. 2015: Waveland press.

40. Phillips, S.J., M. Dudík, and R.E. Schapire. A maximum entropy approach to species distribution modeling. in Proceedings of the twenty-first international conference on Machine learning. 2004. ACM.

41. ESRI, ArcGIS 2015, Environmental Systems Research Institute, Inc: Redlands.

42. Hijmans, R.J., et al., Very high resolution interpolated climate surfaces for global land areas. International Journal of Climatology, 2005. 25(15): p. 1965-1978.

43. Elith, J., et al., A statistical explanation of MaxEnt for ecologists. Diversity and Distributions, 2011. 17(1): p. 4357.

44. Phillips, S., M. Dudik, and R. Schapire, Maxent software for species distribution modeling. Á/< w ww. cs. princeton. edu/schapire/maxent, 2005.

45. Phillips, S.J. and M. Dudík, Modeling of species distributions with Maxent: new extensions and a comprehensive evaluation. Ecography, 2008. 31(2): p. 161-175.

46. Elith, J., et al., Novel methods improve prediction of species' distributions from occurrence data. Ecography, 2006. 29(2): p. 129-151.

47. Flory, A.R., et al., Environmental conditions associated with bat white-nose syndrome mortality in the north-eastern United States. Journal of Applied Ecology, 2012. 49(3): p. 680-689.

48. Hijmans, R.J., Cross-validation of species distribution models: removing spatial sorting bias and calibration with a null model. Ecology, 2012. 93(3): p. 679-688.

49. Phillips, S.J., et al., Sample selection bias and presence-only distribution models: implications for background and pseudo-absence data. Ecological applications, 2009. 19(1): p. 181-197. 
50. Fielding, A.H. and J.F. Bell, A review of methods for the assessment of prediction errors in conservation presence/absence models. Environmental conservation, 1997. 24(01): p. 38-49.

51. Pearson, R.G., T.P. Dawson, and C. Liu, Modelling species distributions in Britain: a hierarchical integration of climate and land-cover data. Ecography, 2004. 27(3): p. 285-298.

52. Glaser, P.H., J.A. Janssens, and D.I. Siegel, The response of vegetation to chemical and hydrological gradients in the Lost River peatland, northern Minnesota. The Journal of Ecology, 1990: p. 1021-1048.

53. Wassen, M. and J. Joosten, In search of a hydrological explanation for vegetation changes along a fen gradient in the Biebrza Upper Basin (Poland). Plant Ecology, 1996. 124(2): p. 191-209.

54. Bartelheimer, M., D. Gowing, and J. Silvertown, Explaining hydrological niches: the decisive role of belowground competition in two closely related Senecio species. Journal of Ecology, 2010. 98(1): p. 126-136.

55. Silvertown, J., et al., Hydrological niches in terrestrial plant communities: a review. Journal of Ecology, 2015. 103(1): p. 93-108. 